\title{
Ludic Unreliability and Deceptive Game Design
}

\author{
Stefano Gualeni* \\ Nele Van de Mosselaer ${ }^{*}$
}

\begin{abstract}
Drawing from narratology and design studies, this article makes use of the notions of the 'implied designer' and 'ludic unreliability' to understand deceptive game design as a specific subset of transgressive game design. More specifically, in this text we present deceptive game design as the deliberate attempt to misguide players' inferences about the designers' intentions. Furthermore, we argue that deceptive design should not merely be taken as a set of design choices aimed at misleading players in their efforts to understand the game, but also as decisions devised to give rise to experiential and emotional effects that are in the interest of players. Finally, we propose to introduce a distinction between two varieties of deceptive design approaches based on whether they operate in an overt or a covert fashion in relation to player experience. Our analysis casts light on expressive possibilities that are not customarily part of the dominant paradigm of user-centered design, and can inform game designers in their pursuit of wider and more nuanced creative aspirations.
\end{abstract}

Keywords: Game Design, Deceptive Design, Deceptive Game Design, Transgressive Game Design, Ludic Unreliability, Implied Designer, Meta-reflexivity, Self-reflexive games.

\section{Introduction}

Within the variety of approaches that game scholars can adopt to explore their object of interest, one possibility that has received increasing attention in recent years is to analyze games as designed, interconnected systems of constraints that are meant to elicit and accommodate specific agential forms. ${ }^{1}$ Such constraints limit how players are able to interact with game systems. In the case of in-game affordances, they may determine the number of tiles per turn that the player can move her pawns, or whether her player character is able to clear a specific height while jumping.

\footnotetext{
* Institute of Digital Games, University of Malta, Malta.

${ }^{*}$ University of Antwerp, Belgium

${ }^{1}$ This perspective is notably advanced by scholars such as Jonas Linderoth (2012) and John R. Sageng (2015). It is also featured in books such as Ian Bogost's (2016) Play Anything: The Pleasure of Limits, the Uses of Boredom, and the Secret of Games, and more recently in C. Thi Nguyen's Games: Agency as Art (2020).
} 
Designed constraints can also feature as interdictions of a more explicitly ideological kind. Games guide and limit player behaviors and attitudes, for example, by imposing in-game criteria for success and failure. Those criteria and precepts are meant to be unquestioningly accepted and internalized by whoever engages with that particular game. During gameplay, however, players can deliberately decide to adopt a critical stance towards the roles and aspirations that they perceive the game implies for them. This critical stance has been studied under the heading 'critical play' in game studies. As a component of critical play, the idea that one can 'play transgressively' is particularly relevant to be discussed in relation to the scopes of this paper. ${ }^{2}$ We are here referring to the notion that some of the functional and ideological boundaries proposed by a game can be actively challenged and transgressed by players. ${ }^{3}$

In the current game studies discourse, most scholars focus on transgressive practices that have either a ludic form (i.e. that are pursued within the boundaries and possibilities of the game in question) or a meta-ludic form that involves the manipulation of the very limitations and criteria for success and failure that characterize a game's agential structure. Other scholars in the field describe transgressive game practices more broadly, identifying them as ways to play that overstep boundaries related to real-life values such as legality, morality, social convention or good taste (see Jørgensen \& Karlsen 2019).

One form of game-related transgression that is rarely discussed in game studies is the possibility for the developers to approach the design of a game transgressively. ${ }^{4}$ In the few published works dedicated to this theme, transgressively designed games are understood to be games that let their players challenge societal norms. In those games, taboos are openly addressed and players are encouraged and incentivized to act immorally. Transgressive design is thus often presented as an inevitably subjective category, since it emerges "as a relational concept that demands a contextual and processual un-

\footnotetext{
${ }^{2}$ Flanagan's work was pioneering in discussing how games can be used by players to question social norms and expectations. Her Critical Play: Radical Game Design labels as ‘subversive play' any player activity intended to critically engage with the boundaries of what is permissible within a game and to challenge the games' intended meanings and underlying ideologies $(2009,57)$. She also lists and discusses a number of ways to play games (and play with games) that can encourage and support this kind of critical attitude. Among these approaches are playing against the game's established goals (i.e., deliberately acting against the values and objectives imposed on the player) and the practice of 'unplaying' (i.e., configuring unanticipated and often absurd in-game scenarios, which also includes the act of 'modding'). Games' resistance to players' transgressive intentions is central in Flanagan's perspective, as it reveals how games are designed in ways that enforce and uphold established conventions and existing (actual) power structures.

${ }^{3}$ Notable efforts in exploring transgressive play include the academic work of Flanagan (2009), Kafai et al. (2009), Tanenbaum (2013), Ford (2018), and Jørgensen and Karlsen (2019).

${ }^{4}$ The little academic attention that has been directed toward transgressive game design has often focused on the possibility for design to allow and invite acts of transgressive play. Holger Pötzsch (2019), for example, identifies transgressive design in design features "that (often unintentionally) enable a break with game rules and mechanics as well as to the practices of creating and exploiting such formal potentials” (50).
} 
derstanding of the phenomenon in question. Transgressivity is that which is perceived as such by someone in some context” (Pötzsch 2019, 49).

In this article, we do not focus on transgressive design understood as an attempt to willfully ignore or overstep social, moral, or personal boundaries, but rather as the deliberate subversion of established game design conventions. We will explore, instead, cases in which the designer voluntarily acts against the values and conventions enforced by the idea of 'best practice'. Precursors of this approach to transgressive design are found in Douglas Wilson and Miguel Sicart's (2010) paper “Abusive Game Design” and Jose Zagal et al.'s (2013) article “Dark Patterns in the Design of Games”. Both texts focus on design practices that call into question the tenets of player-centered design (a paradigm which values clarity, consistency, and fairness in the presentation of in-game content). The two articles listed above propose design perspectives that, in different ways, oppose the fundamental assumption of user-centered design, which states that the designed objects and functions should cater to the users' desires and expectations (see Fullerton 2008, 2). While Wilson and Sicart propose to understand games as mediators of a personal relationship between the player and the designers (a relationship that can be ambiguous and even abusive), Zagal et al. focus on game features that intentionally go against players' interests, often without the player's awareness or consent.

Our focus in this text is on a specific subcategory of transgressive design that significantly diverges from the two perspectives outlined above. The original approach we are presenting here makes use of the notion of the 'implied designer' ${ }^{5}$, that is the conceptualization of the designer constructed by the player on the basis of her evolving interpretation of the gameworld (Van de Mosselaer \& Gualeni 2020). Building on this notion, we will present and discuss the idea of deceptive game design. As will be explained in the next sections, our approach understands design decisions as deceptive when they are deliberately intended to misguide the player in her construction of the implied designer. Moreover - to be recognized as deceptive design decisions in the sense we are proposing here- - these acts need to be carried out by the actual designer to serve the interests of the player. In other words, in deceptive design the designer deceives the players in order to provoke certain aesthetically valuable emotional responses in them-typically surprise, confusion, excitement, estrangement, as well as various combinations of such responses.

\footnotetext{
${ }^{5}$ Although the implied designer is discussed in this article in the singular form, collaborative works of fiction such as movies and digital games are often the products of distributed authorship (Gualeni et al. 2019). Following Gregory Currie (1990, 11-12), we argue that it is unproblematic to posit one implied creator even in such cases. Like Currie, we understand the notion of the implied author to refer not to an actual person, but rather to the sum of the creative intentions that the reader perceives to lie at the basis of a creative work.
} 
In the upcoming sections, we will present and discuss opportunities to design deceptively in both the paraludic and the ludic components of the game artefact. Among the various expressive possibilities that can be pursued with deceptive design, we will particularly focus on its potential to estrange the players and to stimulate them to adopt critical or meta-reflexive attitudes.

\section{Games as Intentional-Communicative Artefacts}

To articulate the understanding of deceptive game design presented above, we propose to understand games as belonging to the category of 'intentional-communicative artefacts' (see Currie 2011, 6): they are created with the intention of being apprehended, used, and enjoyed in specific ways. As intentional-communicative artefacts, games and video games are designed to communicate the developers' intentions to their users in a variety of ways that can be explicit and implicit (see Nguyen 2020, 130-140). This perspective is central to our 2020 paper "The Implied Designer and the Experience of Gameworlds” (Van de Mosselaer \& Gualeni 2020), where we present the notion of the implied designer in analogy to the 'implied author' in literary theory. In that text of ours, we introduce the implied designer as

the conceptualization of a designer that the player constructs on the basis of their dynamic interpretation of the gameworld. To this inferred figure, the player ascribes all those intentions that they think lie at the basis of the creation of the gameworld in question.

To better understand this notion, it is fundamental to highlight that the aspirations and quirks of an implied designer are inferred by the player first and foremost from elements and qualities of the designed artifact. Inferences about what the designer wants and means are primarily derived from experiencing the gameworld (together with its interfaces, menus, and so on), as well as from paraludic materials such as trailers, advertisements, box art, and user manuals. In addition to the evidence offered by the observable qualities of the game artefact, the player also pieces together the intentions of an implied designer on the basis of the player's own sociocultural background, her level of game literacy as well as her subjective sensitivities and preferences. In the field of narratology, Wolf Schmid (2009) similarly discusses the figure of the 'implied author' as emerging from both objective and subjective elements of one's relationship with a creative work:

On the one hand, it has an objective component: the implied author is seen as a hypostasis of the work's structure. On the other hand, it has a subjective component relating to reception: the implied author is seen as a product of the reader's meaning-making activity... At any rate, it must be remembered that, like the readings of different recipients, the various interpretations of a single reader are each associated with a different implied author. Each single reading reconstructs its author. (162) 
In agreement with Schmid, in our 2020 paper we argued that a specific implied game designer is constructed by the player during each play session. As already mentioned, we considered the elements and qualities of a gameworld as the primary indications of the designer's goals and aspirations (Van de Mosselaer \& Gualeni 2020). Some of these intentions can be explicitly presented in the game, for example in the case of pop-up text boxes that inform players about what to do and where to go to complete a certain in-game task. Similarly, non-player characters (NPC's) can teach players how to control their in-game avatars, how to organize their belongings into the inventory, how to perform advanced fighting techniques, and so on. Other clues about the gameworld and its meaning can be more subtly embedded in the gameworld: a path of blood spatter on the floor can give players hints as to what might have happened in a room, an impending sense of danger, and information as to where the player might need to go next. Similarly, the presence of enemies that are too difficult to defeat usually imply that the players are supposed to first increase their fighting skills in less threatening areas of the gameworld. Also, the fact that the game rewards players for certain actions (for instance in the form of in-game currency or experience points) offers itself as an evident indication that those actions are to be considered desirable and worthy of repetition. All these ludic traits and elements can thus be interpreted as clues about how to understand the gameworld and how to behave within it, and this is possible precisely because players perceive these elements to be purposefully designed. The intentions of the designer are implied in these aspects of gameplay and guide players' behaviors and the formulation of their in-game objectives.

In our 2020 paper, we specifically approached the concept of the implied designer from the perspective of the player, investigating how her level of game literacy is a factor in how she infers the implied designer. In this article we will instead focus on how actual designers can make expressive use of the figure of the implied designer. In other words, in this text we will address how actual game designers can manipulate and influence players' construction of the implied designer in order to confuse, surprise, and even alienate them. As we are going to argue below, this is pursued by the actual designer through the projection of certain (misleading) intentions via the game artefact.

Within design studies, it has been argued that the effectiveness of a certain design can be judged by the degree to which the intentions of the designers and the interpretations of consumers correspond (see Kazmierczak 2003, 48-49; Crilly et al. 2008, 439). Indeed, in a general sense, we might say that the success of an intentionalcommunicative artefact depends on how well it can convey its intended function to its users. If we apply this criterion to the design of digital games, and rephrase it in terms of the implied designer, we can say that digital games should ideally be designed in a 
way that makes it likely that the players infer the intentions of the implied designer in a manner that reliably inform them about how the game functions. ${ }^{6}$ In the upcoming sections of this article, we will examine this design principle by investigating cases where actual game designers did not (or failed to) adhere to it. We argue that these cases constitute examples of 'ludic unreliability', and we will show how game designers often intentionally set up ludically unreliable game scenarios. More specifically, we will discuss the aesthetic and critical value of these willful transgressions of the canonical objectives of intentional-communicative design. With that aim in mind, the final sections of this article will analyze paradigmatic games that deliberately project misleading designer's intentions.

\section{Ludic Unreliability}

Ludic unreliability occurs when a game signals certain possibilities and functionalities that diverge from how the game actually functions. In other words, a ludically unreliable game does not function in the way the player would reasonably expect. As discussed in the previous section, these expectations are conceptually bundled in the figure of the implied designer, by which the players infer and refine in their relationship with the gameworld, its associated paraludic material, and relevant information made available online by the community of players (see Van de Mosselaer \& Gualeni 2020). We identify two distinct types of ludic unreliability:

- Unintentional unreliability (i.e. accidental sources of unreliability in games, such as mistranslations, programming mistakes, glitches, and so on)

- Intentional unreliability (i.e. unreliable game elements deliberately designed to be part of the game experience.)

Although this article focuses on the second category, we deem it useful to first explain what is meant by 'unintentional ludic unreliability', since it clarifies the specificities of the intentional variant.

Unintentional ludic unreliability consists of an accidental divergence between projected creative intentions and the way a game actually functions. As discussed above, such divergences are generally undesirable, as they might compromise players’ appreciation of a certain game. Ideally, “designers must actively attempt to influence consumer

\footnotetext{
${ }^{6}$ To anticipate and address the potential criticism that this paper takes an approach tainted by the 'intentional fallacy', we want to clarify that our claim is not that games are in any way fixed or limited by the actual intentions with which they were created. We do not intend to propose that game interpretation is, or should be, influenced by the actual intentions with which a game was created. We argue, instead, that players understand in-game events and situations on the basis of the intentions they believe or infer to lie at the basis of the game's creation. In that sense, the perspective we present here is compatible with the idea within design studies that it is important for designers to anticipate how their product might be interpreted, as it is interpretation rather than intention that determines how that artefact will be used (see Crilly et al. 2008).
} 
interpretation, and anticipating those factors that might lead to problematic interpretations is an important part of that process" (Crilly et al. 2008, 439). The best efforts on the designers' part notwithstanding, ludic unreliability can still occur due to design choices that give rise to ambiguities and misinterpretations, because game functionalities were insufficiently tested, or due to poorly translated instructions or in-game hints.

One example of unintentional ludic unreliability can be observed in FromSoftware's Sekiro (2019). Near a particular temple in this game, the player-character (Sekiro) meets an old woman asking for rice. At that point in the game, the player has nothing to offer her. Later in the same level, however, Sekiro happens upon a merchant selling an item called 'five-color rice'. When the player buys this item and returns to the woman, there is no dialogue option to offer her the 'five-color rice', nor does she react to the 'fivecolor rice' being thrown all over her. She simply continues to ask for rice. The problem with this in-game scenario is that the 'five-color rice' is an item that the player can use to create waypoints in the gameworld, rather than the quest item needed here. In this case, ludic unreliability is caused by the game inadvertently suggesting a course of action to players that is not only ineffective, but also not addressed by the developers in terms of in-game feedback.

A game experience can also be unreliable because of mistakes and confusing information that do not pertain directly to the gameworld in question, but rather to its paraludic material. One glaring example of this kind of unreliability can be found in the manual for the NES version of the action-adventure digital game The Legend of Zelda (Nintendo EAD 1987). The manual claims that Pols Voice, an enemy in this game, has a weak point: "he hates loud noise" (Nintendo EAD 1987, 36). Originally, this was intended to be a clue for the Famicom version of The Legend of Zelda (Nintendo EAD, 1986), in which Pols Voices can be killed by yelling into a microphone that was embedded in the console's controller. As the NES controllers were not equipped with a microphone, it was impossible to kill these enemies by producing loud noises in the actual world. Unfortunately, the manual was not adjusted for the NES version of the game, thus puzzling players with this mysterious hint. As a result, some players thought that the sound from the flute-like in-game item called a 'recorder' could dispense with the annoying Pols Voice. Playing the recorder in the world of Hyrule has, however, no effect on these enemies.

These examples show that ambiguity and unexpected behavior are undesirable in games and that the developers should do their best to try to avoid them. Reliably projecting consistent and unambiguous intentions on the part of the designers and efficiently informing players about how the game functions are central tenets of good, playercentered game design. These traits and qualities are customarily considered particularly desirable in the design of a game's tutorial sections and in the initial phases of the play- 
er's engagement with a gameworld, where it is vital that new players are provided clear information and well-defined purposes.

And yet, designers sometimes deliberately choose to project intentions that diverge from how their game actually functions and/or from its ostensible criteria for in-game success. Unlike the kind of ludic unreliability that occurs accidentally, intentional ludic unreliability need not hinder or degrade the experience of the game, but can contribute to it. By making purposeful use of ludic unreliability, game designers can influence players to act and feel in particular ways within (and toward) a gameworld. They might, for example, put players in unexpected or surprising situations by implying certain intentions on the part of the designer that are later proven false or inaccurate. Deliberate ludic unreliability can be used in many ways with a variety of expressive outcomes, including tricking players into investigating meaningless clues-for example by designing red herrings into the game-or making a game feel more challenging by exaggerating the magnitude of the threats that players will have to face.

As already clarified in the introduction, we propose to call design that causes intentional ludic unreliability deceptive game design. Before venturing into the various expressive possibilities for deceptive game design and exploring some paradigmatic cases, it might be important to emphasize that one of the experiential effects of artefact unreliability most often discussed-regardless of its intentional or unintentional constitution-is that of a communication breakdown which leads to user estrangement (see Crilly et al. 2008, 441; Gualeni 2019). In those moments, the user (or in our case the player) becomes more acutely aware of the medium that is being used and of one's own conventional expectations towards it (ibid.). Accordingly, game designers can deliberately implement deceptive decisions within their games with the goal of shocking and alienating players. They can do this by manufacturing game malfunctions or by exhibiting the artificiality or 'constructedness' of the gameworld, thus breaking players' expectations towards the consistency and trustworthiness of this gameworld. We are referring, for example, to situations where the narrative of a digital game breaks the 'fourth wall', or when a game deliberately displays debug information or background geometry, or triggers visual or auditory glitch-alikes (see Gualeni 2019). As we will explain later, by exposing the artificiality and technical setup of digital games, deceptive game design can stimulate the emergence of "critical and/or satirical perspectives on the ways in which digital games themselves are designed, played, sold, manipulated, experienced, and understood as social objects” (Gualeni, 2016). ${ }^{7}$

\footnotetext{
${ }^{7}$ In the field of game studies, the possibilities for games to encourage meta-reflexivity (or 'self-reflexivity') have previously been discussed by Rapp (2007), Gualeni (2016), Bonello Rutter Giappone (2017), and Waszkiewicz (2020).
} 


\section{Deceptive Game Design}

We consider a design decision deceptive when it is meant to deliberately mislead the player concerning the meanings or functions of some elements of the game by projecting specious designer's intentions. Deceitful information and hints can potentially be implemented in any component of the experience of gameplay: what players are allowed to do in the gameworld, what they will be rewarded for, which narrative path they should follow, and so on. Deceptive design decisions, in other words, transgress the tacit agreement between players and designers that the game discloses an interactive gameworld that the players can trust and buy into.

In the specific and benevolent way we are discussing deceptive game design, however, the transgression is not malicious, but is meant to produce desirable experiential and emotional effects on players. Our approach to transgressive design thus significantly differs from the 'abusive' or 'dark' design practices discussed above. Like abusive design and dark design, however, deceptive design also relies on a degree of dishonesty on the part of the actual designer.

To refine and add detail to the way we are proposing to frame deceptive design, we introduce a taxonomy of deceptive design practices that considers how the designed deception features in the context of player experience. We propose a distinction between:

- design deceptions in which the deceit (the 'lie') itself serves a game-related purpose, and

- design deceptions in which it is the revelation of the dishonesty (the admission of having 'lied') that is intended to affect the players.

In the first category, covert deceptions, it is the deceitful content of the game that affects the player. In the second category, that of overt deceptions, players' experiential and emotional relationship with the game is transformed by the game's own disclosure of having misled them. More simply put, overt deceptions primarily affect players through the in-game admission that the game itself was deceitfully designed.

\section{Examples of Covert Deceptive Design}

In the case of covert deceptions, the creative intentions projected by a game diverge from how that game actually functions. We are not claiming that covert deceptive design decisions need to remain hidden from players throughout gameplay. Rather, transgressions in this category can be recognized as having an emotional effect on players as long as they are unaware of the deception. While players are ignorant of their deviousness, covert deceptive design decisions can make gameplay more thrilling, more meaningful, and often also less frustrating. 
A clear example of a deception that is effective as long as the player is unaware of having been deceived is found in Ninja Theory's 2017 fantasy action-adventure digital game Hellblade: Senua's Sacrifice. In Hellblade, a deliberately deceptive design feature is presented to the player in the opening section of the game, after the first, scripted death of the player-character Senua. Throughout gameplay, Senua is either hallucinating or experiencing dissociative events, and, during this initial scripted section, one of the voices in her head informs her (and the player) that 'dark rot' (or 'the darkness') has taken hold inside her. This sickness will keep spreading from her arms toward her head- - "the seat of the soul"- - until nothing is left of her. This scene, taking place just after the first scripted death of the character, is a strong suggestion of the existence of a permadeath mechanic, implying a risk that the player may irrevocably lose their progress, together with Senua's sanity, should the player let her die too many times (see Figure 1). The game does not, however, actually feature a permadeath mechanic or any long-term penalties for frequent in-game deaths. The deceiving information was planted by the designers to add gravitas to the player's actions, with the objective of increasing their emotional engagement with the game's outcomes and with one of its central narrative themes-mental illness.

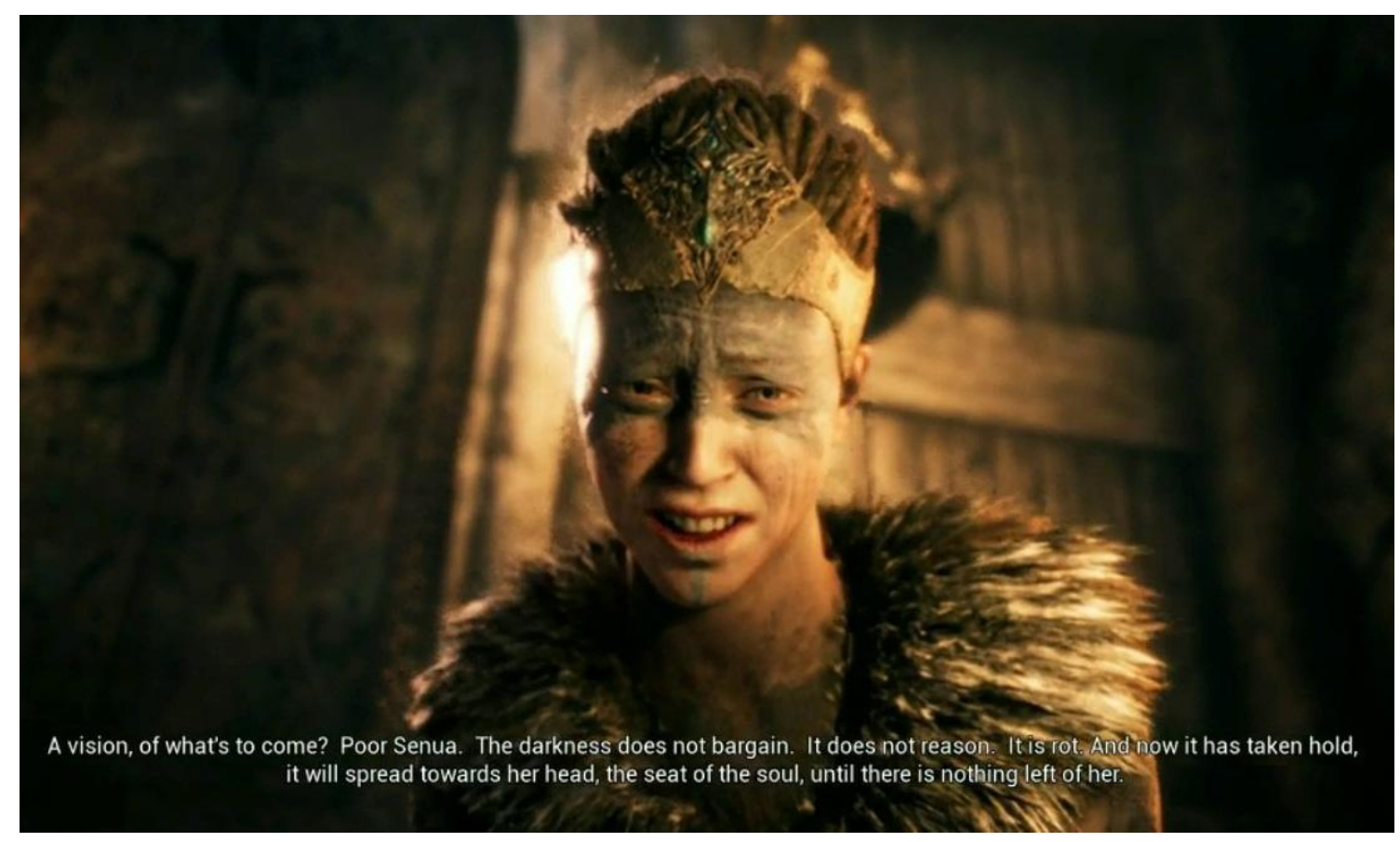

Figure 1. A screenshot of Hellblade: Senua's Sacrifice (Ninja Theory 2017)

Here, the purpose of the deception is precisely the uncertainty it instills within the player, who needs to figure out how this mysterious 'dark rot' will affect them. This particular deception is never revealed to the player during the gameplay, but the fact that 
the permadeath mechanic is not part of the game can be either intuited by players or found in online interviews and discussions about the game. "A large part of mental illness-psychosis in particular-is about fear”, explains Hellblade's creative director Tameem Antoniades:

\begin{abstract}
We were looking for ideas of how you introduce fear, and one of those ideas was the permadeath mechanic. It's the only time we're very explicit about what will happen to you in the game. [...] But it's your interpretation as a player that taints the meaning behind it. That's something we wanted to do on purpose, because with mental illness it's your frame of mind that interprets the world, and that can cause you distress. (Purslow 2017)
\end{abstract}

A second example of deceptive design that elicits a certain effect while remaining concealed from the player is found in the independent digital game Waldo.io (Big Breakfast Collective 2019). Upon launching, the game prompts the player for the username they intend to use. After a username has been inputted, the game connects to the internet and automatically looks for an available multiplayer match. The username chosen by the player soon appears among those of their competitors in a game lobby (see Figure 2).

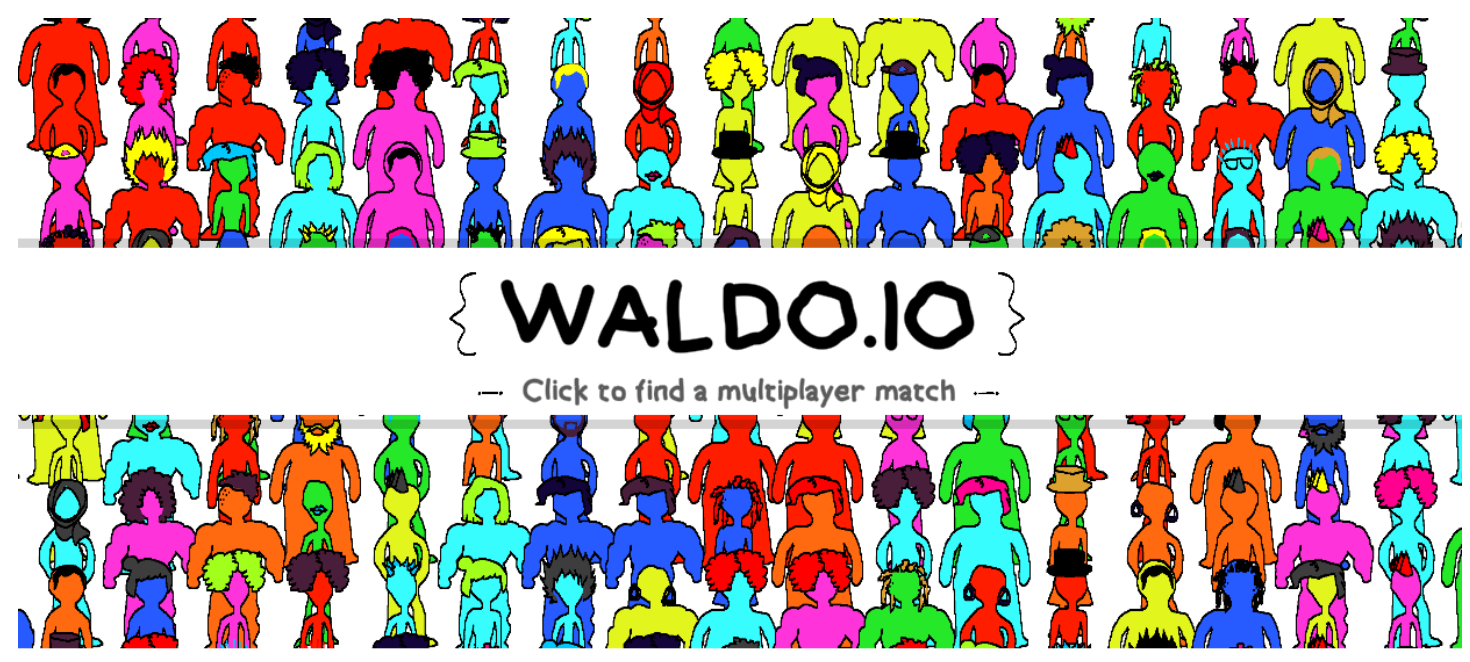

Find Waldo Before the Others!
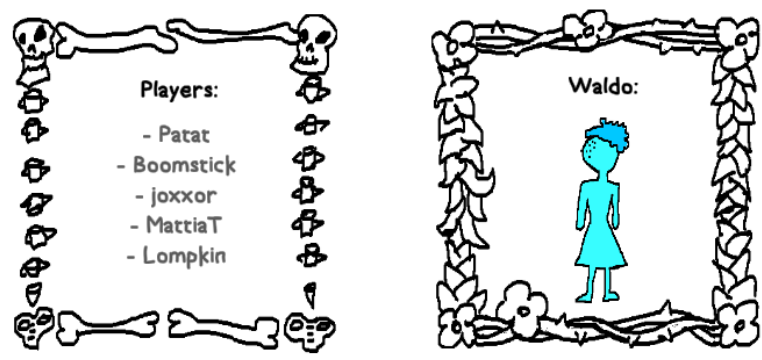

Figure 2. Two screenshots of Waldo.io (Big Breakfast Collective 2019) showing the design elements meant to mislead the players about the kind of playful interactions they are about to experience. 
Waldo.io is, however, a single-player, hidden-object digital game. The whole preliminary setup of picking a username and entering a multiplayer game lobby are part of the game's deceptive design. On the game's itch.io website, the developers of the game explain this as follows:

There's a fake lobby, and the game generates usernames for everyone but you. We even went out of our way to make sure you can't play without an internet connection... And you know what? The multiplayer feels real. The "other players" are allowed to win, and sometimes they do. (Traverso 2019)

As stated on its dedicated webpage, Waldo.io was created to give players the thrilling feeling of interpersonal competition, a feeling that relies on the player falling for this deception, which the Big Breakfast Collective designed in the preliminary phases of the game experience.

Another way for game designers to covertly project deceptive intentions to their players is by lying about the very genre of the game. Such deception can already take shape when players engage with misleading paraludic material. The official promotional trailer of The Fullbright Company's 2013 single-player first-person digital game Gone Home is a paradigmatic example of a design deception of this kind. The game's official trailer unsubtly relies on a wide range of tropes characteristic of the horror genre, including a stormy night, an abandoned mansion shrouded in darkness, all the phones being disconnected, mysterious apparitions, and a growingly tense musical score. The eerie and frightening situations promised in the trailer are, however, misleading in terms of the actual gameplay of Gone Home. Although the game does indeed take place in a lonely mansion and contains the horror tropes hinted at in the trailer, it is not a survival horror game and does not feature any of the expected threats or dangers. Gone Home is an intimate exploration of the stories, feelings, and relationships weaving the protagonist's family together. ${ }^{8}$ This deception does eventually become evident to players who finish the game without ever encountering any of the implied jump scares or lifethreatening situations. By that time, however, the trickery has already fulfilled its purpose of making the gameplay thrilling and tense because of the player's expectation of scary, unexpected events.

Not all design transgressions intended to have an effect on players who are unaware of the deception are meant to add gravitas to players' actions, or to make them feel more fearful and insecure than they would normally be. Some deceptions are covertly present

\footnotetext{
${ }^{8}$ It is not implausible to suppose that The Fullbright Company adopted this transgressive design strategy to make their debut game appealing to a player base they deemed more attracted to action-oriented and conflict-packed titles over what is often pejoratively termed 'a walking simulator'. If this speculation corresponds to the actual motivations, however, the design of the official trailer for Gone Home would fit the 'dark' category better than the 'deceptive' one.
} 
to make players feel more skilled than they actually are. Among those deceptive design features are those cases in which the game underhandedly regulates the difficulty ofsay - a boss battle or a particularly challenging area of the gameworld, for instance by removing some of the threats or decreasing the threats' damage output. Other game functionalities of the same kind can be recognized in those informally referred to as 'coyote time" ${ }^{\text {, }}$ or in features that subtly assist players with their aim. These deceptive features are clearly not meant to damage or patronize the players, or to take advantage of them, rather they are the game design equivalent of 'white lies': small deceptions that make the experience of gameplay smoother and more satisfying for the players.

\section{Examples of Overt Deceptive Design}

In contrast to the examples discussed in the previous section, there are game design deceptions that are revealed to the player during gameplay, and strategically so. This 'coming clean' in the game is meant to have specific emotional and experiential effects on players that stimulate them to reframe and re-evaluate their own understanding of and engagement with - the game

The fantasy action-adventure role playing digital game Undertale (Fox 2015) offers several examples of this kind of transgressive design. For instance, the game does not initially explain the true meaning of the game statistics labelled 'LV' and 'EXP' that are shown to the player during fight scenes. In line with the conventions of the roleplaying games (RPG's) genre, LV and EXP are likely to be understood by the player as indicating, respectively, the player-character's skill level and quantity of experience accumulated. In RPG's, the presence of these variables characteristically invites players to engage in activities such as defeating NPC's and hoarding in-game resources, which are pursuits that customarily increase the level and experience values, typically by strengthening the player's chances of in-game success. This initial assessment on the player's part is further reinforced as they observe that the value of the EXP variable increases when killing NPC's. Only later in the game is the meaning of the two variables clarified: LV corresponds to 'Level of Violence', while EXP indicates 'EXecution Points'. The player is then informed that, by heedlessly following conventions, they have pursued morally unacceptable acts of selfishness and viciousness (see Figure 3).

\footnotetext{
${ }^{9}$ In digital game design, 'coyote time' indicates the presence of a number of frames during which a player-character can still execute a jump after having run off a ledge or a cliff. It was named after Wile E. Coyote (a character in the Looney Tunes animated series), who popularized comically unrealistic behavior of this kind.
} 


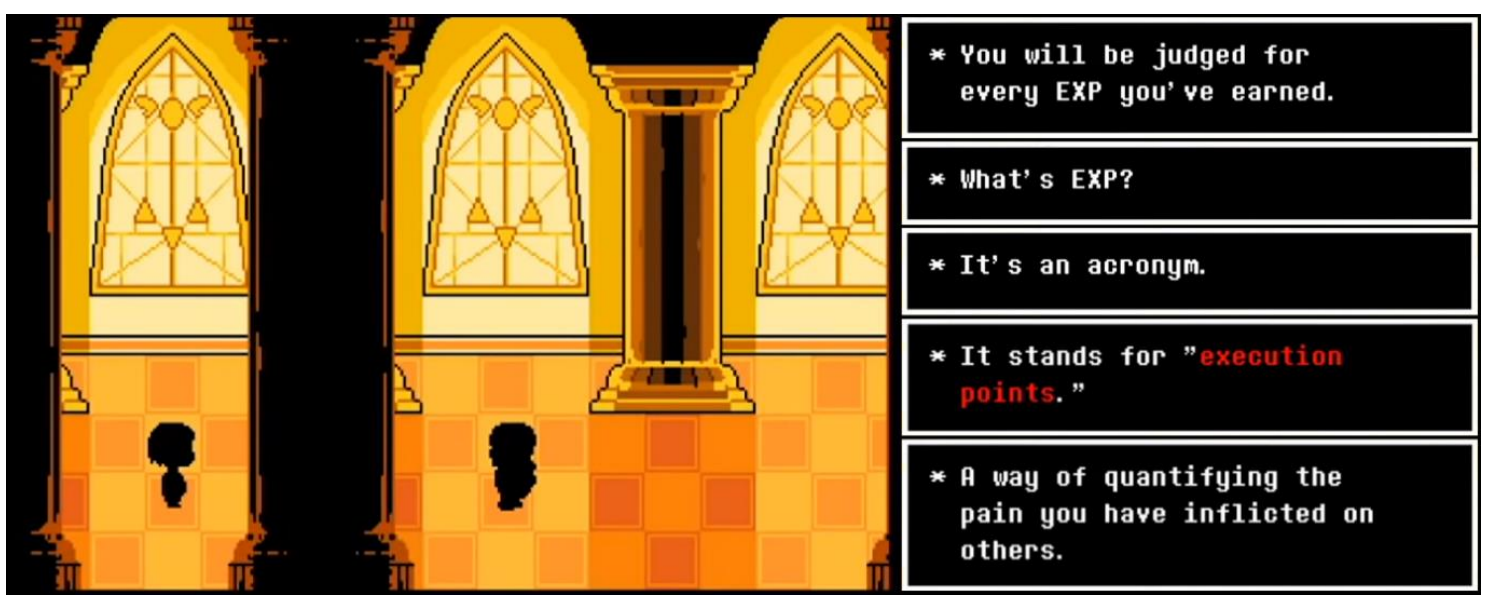

Figure 3. A composition of screenshots taken from Undertale (Fox 2015) showing the monologue in which the game finally reveals the intended meaning of the game variable EXP.

Another example of a revealed design transgression is the infamous marketing baitand-switch involving the central player-character of the action-adventure stealth digital game Metal Gear Solid 2: Sons of Liberty (Kojima 2001; Paterson et al. 2019, 82; Youngblood 2017). In the first section of the game, which was also the pre-release demo level and the source of most of the game's marketing material, players control the series' primary protagonist, Solid Snake, who is a former Green Beret and war veteran. The belief that Metal Gear Solid 2 would be played as Snake was reinforced by paraludic material such as the game box art and the official posters centrally featuring the series' figurehead (see Figure 4). However, only the opening section of the game is actually played as the war-hardened Snake. Throughout the rest of Metal Gear Solid 2, the player takes on the role of Raiden, an inexperienced rookie who is treated as an imbecile by his superiors. 


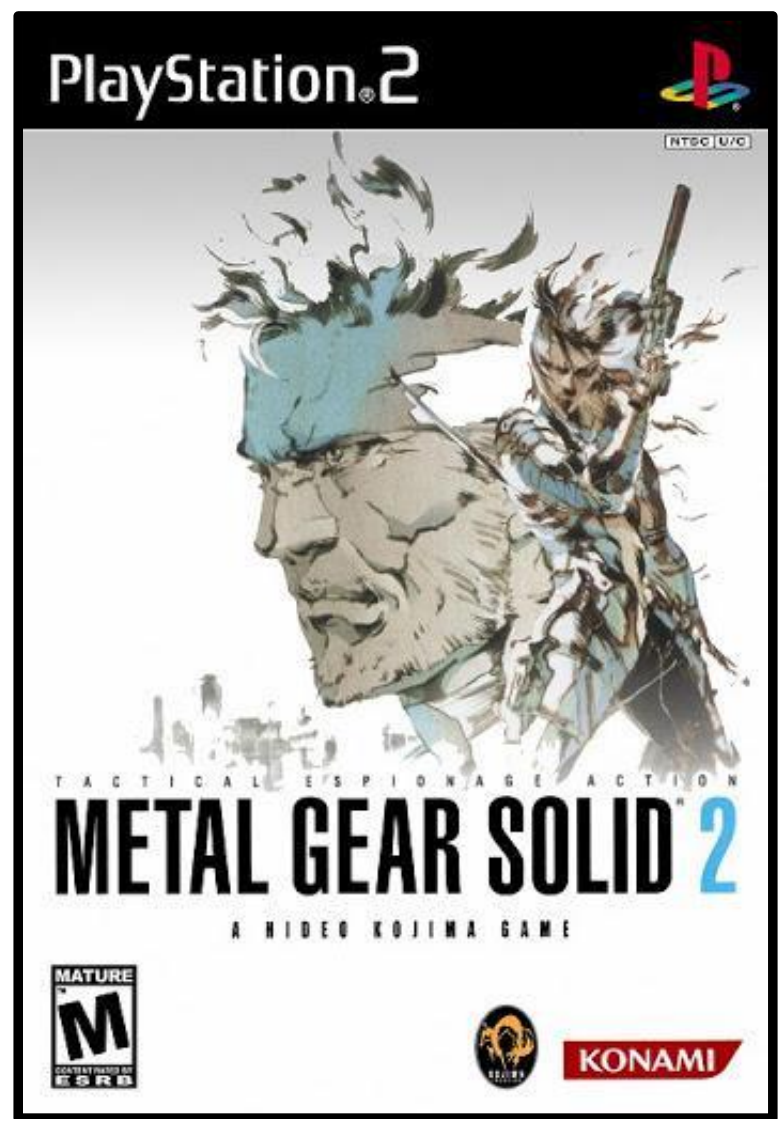

Figure 4. The box art for Metal Gear Solid 2: Sons of Liberty, with Solid Snake's head depicted in the background and Raiden portrayed in the foreground (Kojima 2001).

Hideo Kojima, the director and lead designer of the series, was asked in an interview whether he was concerned about the fans' reactions to this design choice. He responded "[n]ot really. In a sequel you have to meet people's expectations, but you also sort of have to go against them and deceive them, I think”. (Keighley 2012)

Another design deception intended to have a specific effect on the player when its deviousness is revealed can be seen in the single-player fantasy action RPG NECESSARY EVIL (Gualeni et al. 2013). This experimental game presents a very traditional player interface featuring an energy indication and item slots, suggesting a canonically oppositional and instrumental relationship with the gameworld (see Figure 5). 


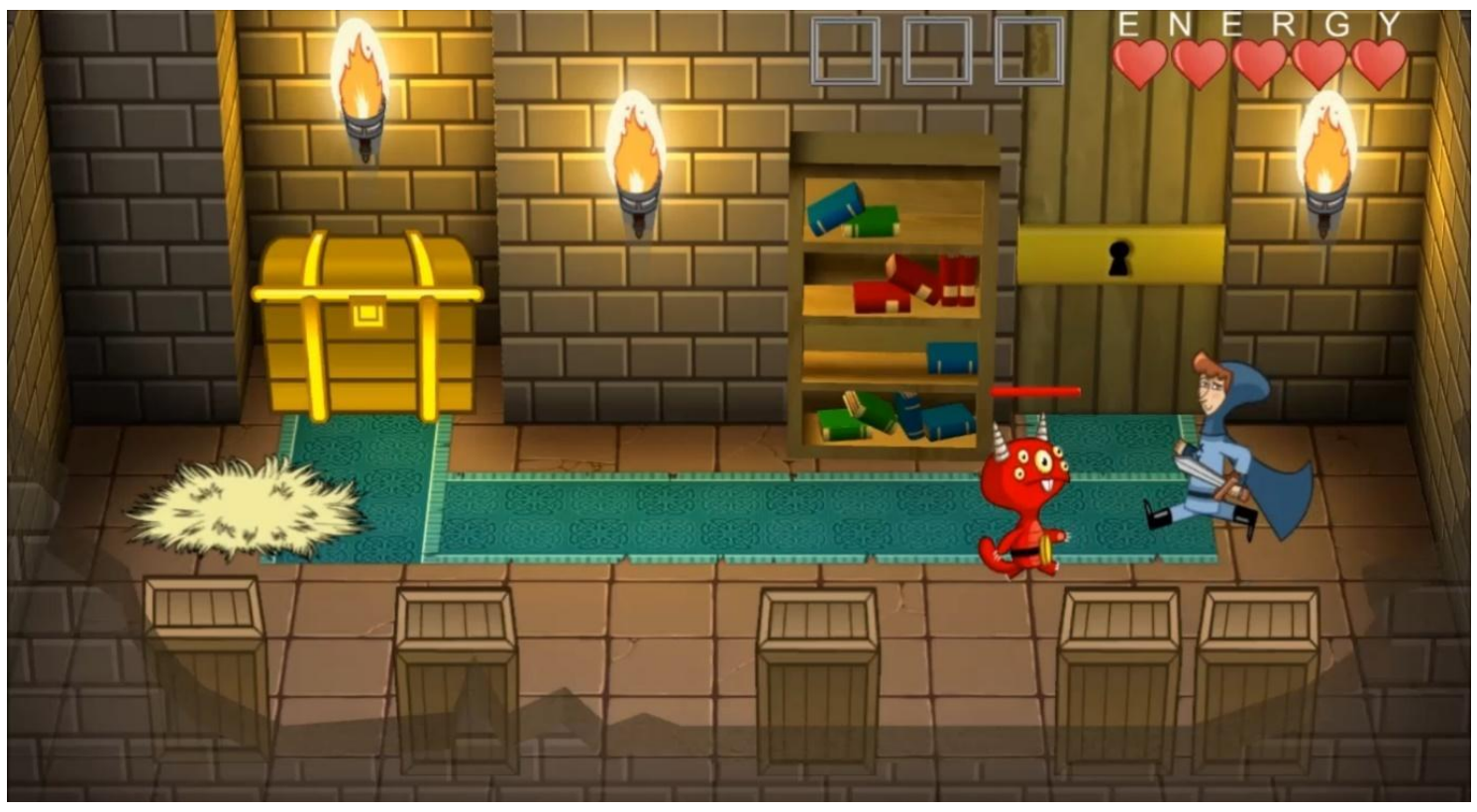

Figure 5. A Screenshot of the combat phase of NECESSARY EVIL (Gualeni 2013).

The interface, however, does not keep track of the health or the possessions of the player-controlled character (a small, horned creature), but rather of those of the bluecaped NPC hero. This second character enters the room only after a few minutes of gameplay, giving the little monster just enough time to wake up and find itself locked inside and without any options to meaningfully interact with the gameworld. Its little red paws cannot open the door, the chest contains nothing for it, and the objects in the room respond to the player's actions as if they were cheap theatrical props.

The fact that the interface deceptively tracks the progress of the NPC hero has an expressive role that contributes to the player experience intended by the designer-one in which the player is surprisingly not the center of the narrative of the gameworld. According to the designer, the player will eventually understand that the gameworld is not meant to

[...] be enjoyed or explored by the horned monster. The little monster merely poses a challenge among many others: it is something for the hero to overcome in order to continue on his intrepid quest. These design decisions were meant to elicit a sense of marginality in the players, and to experientially reveal to them what a virtual world feels like when that world is designed around someone else's perceptions, needs, and narrative progress. (Gualeni 2016)

The examples of overt deceptive design that were presented up until this point are consistent in their evident intent of unsettling players and offering them a new perspective on the game and the intentions of the implied designer. For some overt transgressions, however, the exposed deception is also intended to have further consequences within the game experience. After players are made aware of the unreliable intentions projected by the implied game designer, they are likely to adjust their inferences and 
change their in-game behavior accordingly. The following two examples are from games that reveal their own deceptiveness to provoke a feeling of alienation and estrangement in the player, affecting their future choices and experiences in the gameworld.

The first example is found in the aesthetic presentation of the side-scrolling actionplatformer digital game Syobon Action (also known as Cat Mario; Chiku 2007), which unmistakably references the iconic action-platformer Super Mario Bros. (Nintendo EAD 1985; see Figure 6).

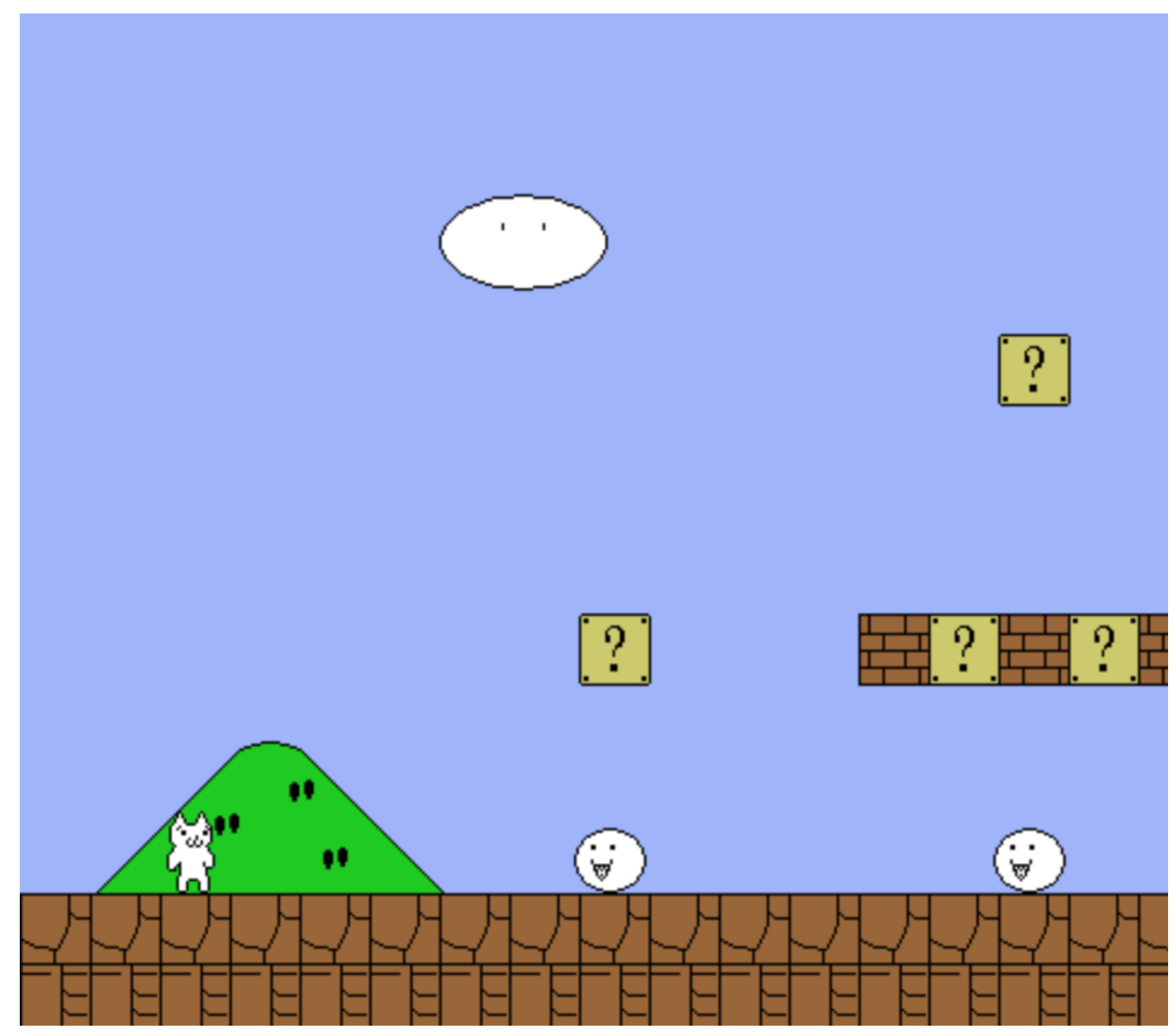

Figure 6. A screenshot of Syobon Action (Chiku 2007).

By appearing similar to Super Mario Bros., Syobon Action invites the player to engage with its gameworld as if the two games functioned according to similar principles and had similar expectations of the players. When playing Syobon Action for the first time, this indeed might appear to be the case: the feline player-character seems to respond to player input in a way that is similar to Mario in Super Mario Bros. and to have analogous relationships with the elements populating its gameworld. Soon, however, 
Syobon Action reveals its true colors, shattering the player's sense of familiarity by introducing behaviors and challenges that are not only inconsistent with those encountered in Super Mario Bros., but are also internally inconsistent. The game was designed to relentlessly surprise and frustrate the player. Despite its reassuring, familiar appearance, Syobon Action is a punishing game that exclusively relies on exceptions. The game can only be mastered in a trial-and-error fashion, as it does not allow for the development of any systematic knowledge about its functioning. Like similar titles such as I Wanna Be the Guy: The Movie: The Game (O’Reilly 2007) or Trap Adventure 2 (Oshiba 2016), it is obvious that the design of Syobon Action does not aim to maximize accessibility and user satisfaction. Instead, by surprising and frustrating its players, the game imposes a critical distance onto the players, and makes them question their very reliance on established game conventions and game values, such as fairness and internal consistency.

Another famous instance of design deception that prompts the player to expect further deceptions is found in the Dark Souls series (FromSoftware 2011). In this medieval fantasy action-adventure RPG series, players wander through somber, dilapidated environments under the constant threat of being tricked, trapped, and assaulted. Their motivation for pressing on through this stressful experience is an inherent sense of progress, and the desire to obtain rewarding in-game resources, such as currency, equipment and consumables that can help the players through the many hardships they face. In Dark Souls, as is typical in games set in fantasy medieval worlds, the best sources of loot are presented as large, battered chests. The association between chests and desirable ingame resources is established through their repeated use in fantasy fiction in general, and is also reinforced in Dark Souls. In the initial areas of the game, in fact, chests do indeed contain items that are precious, useful, and rare. In later sections of the game, however, these chests diverge from the implied canon. Upon prying certain chests open, the player discovers that they are actually 'mimics'.

Mimics are a recurrent trope in Japanese RPG's. They are powerful creatures that feed on adventurers after attracting them by appearing to be chests (see Figure 7). A player encountering a mimic for the first time is likely to be shocked by this event. This design transgression deliberately reinforces the feeling that the gameworld is hostile to the player and unreliable, which — at least in the specific case of Dark Souls-also contributes to making the game more threatening and mysterious. Indeed, after meeting their first mimic, players are very likely to develop the habit of carefully approaching and examining every chest in the game, having inferred an implied designer who can trick them into a misplaced sense of confidence and into being devoured by chest monsters. 


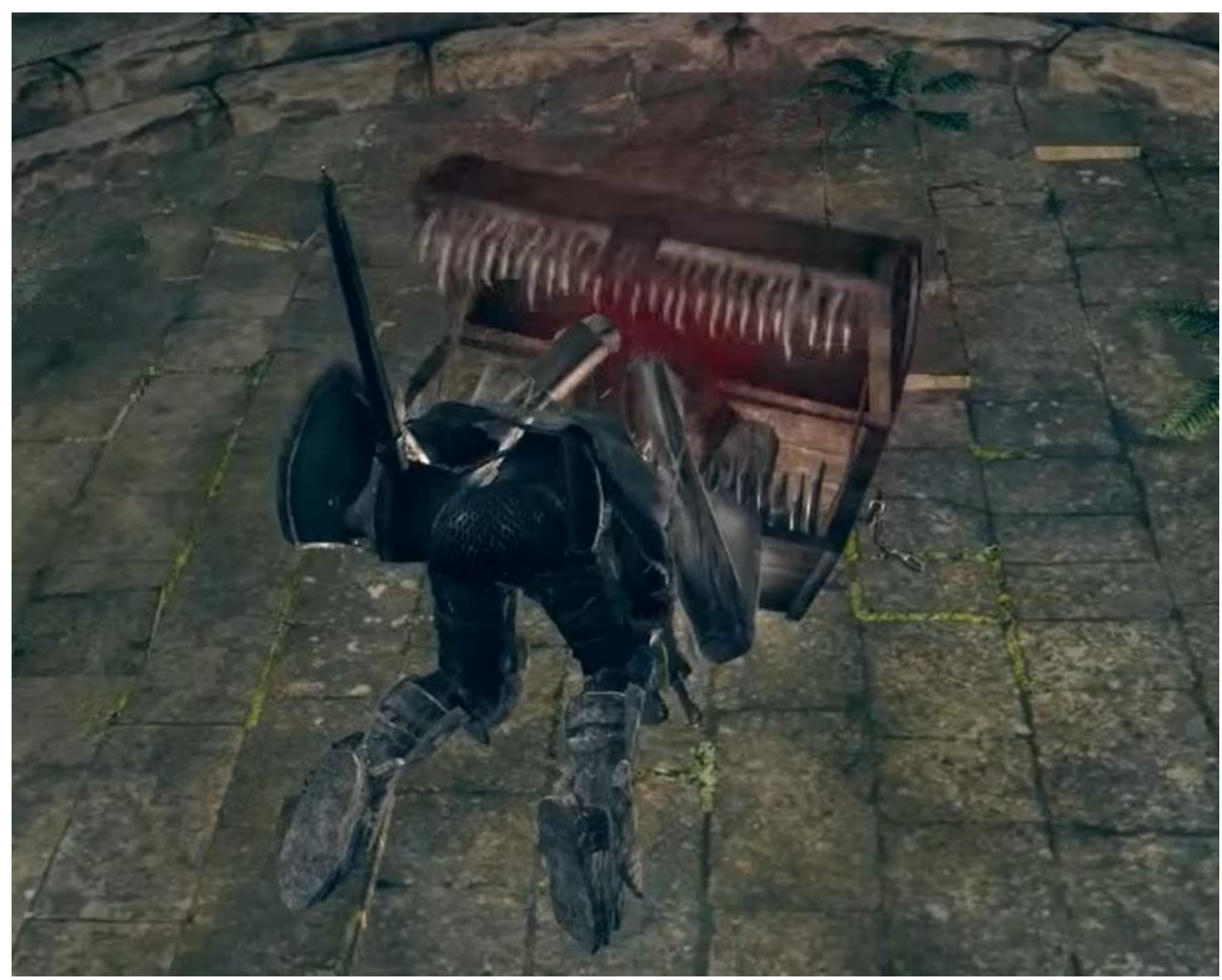

Figure 7. A mimic attacking the player-character in Dark Souls (FromSoftware 2011).

\section{Concluding Thoughts}

Drawing from narratology and design studies, this article made use of the notions of the 'implied designer' and 'ludic unreliability' to understand deceptive game design as a specific subset of transgressive game design. In the first half of our text, we presented deceptive game design as the deliberate attempt to misguide players' inferences about the designer's intentions in ways that give rise to experiential and emotional effects that are in the interest of players.

After having introduced a general definition, we proposed a distinction between two varieties of deceptive design approaches based on whether they operate in an overt or a covert fashion in relation to player experience. Leveraging these ideas, the second half of the paper provided close readings of some exemplary cases of deceptive game design decisions, emphasizing their various traits and experiential goals. Game examples included Hellblade: Senua's Sacrifice (Ninja Theory 2017) and Waldo.io (Big Breakfast Collective 2019), which feature cases of covert design deceptions. The game Undertale (Fox 2015) was discussed as an example of a game that is deceptively designed in an overt fashion. 
While the examples of covert deceptions reveal the use of deceptive design to produce desirable emotional and experiential effects on players, overtly deceptive games are typically designed to estrange players, and invite them to adopt a metareflexive stance. By deliberately surprising and frustrating their players, games like Syobon Action (Chiku 2007) and NECESSARY EVIL (Gualeni 2013) purposefully disincentivize these players from trusting the designers' intentions and from immersing themselves into the gameworlds in question. We have argued that when players find themselves in that estranged and inquisitive state, they are likely to question their reliance on established game conventions. From that detached stance, players are also likely to become hesitant to take for granted that the game experience is going to be fair, internally consistent, or somehow rewarding. Overtly deceptive games can thus be recognized as inviting their players to develop a critical relationship with conventional game design tropes and, in particular, with regard to how they infer and interpret the intentions of the game designer.

\section{Games}

Big Breakfast Collective (2019). Waldo.io [Windows]. Digital game developed by Big Breakfast Collective, available online at: https://big-breakfast-collective.itch.io/waldoio, retrieved on March the $6^{\text {th }}, 2021$.

Chiku (2007). Syobon Action [Windows]. Digital game developed by Chiku, available online at: retrieved on August the $4^{\text {th }}, 2021$.

Fox, T. (2015). Undertale [Windows]. Digital game developed by Fox, T. and published by Fox, T.

FromSoftware (2011). Dark Souls [PlayStation 3]. Digital Game directed by Miyazaki, H., and published by Namco Bandai Games.

FromSoftware (2019). Sekiro: Shadows Die Twice [PlayStation 4]. Digital Game directed by Miyazaki, H., and published by Activision.

Gualeni, S. (2013). NECESSARY EVIL [Windows]. Digital Game developed with Dino Dini, Jimena Sánchez Sarquiz, Marcello Gómez Maureira, and Allister Brimble, available at online at https://evil.gua-le-ni.com, retrieved on August the $4^{\text {th }}, 2021$.

Kojima, I. (2001). Metal Gear Solid 2: Sons of Liberty [PlayStation 2]. Digital Game Developed by Konami and Published by Konami.

Ninja Theory (2017). Hellblade: Senua's Sacrifice [PlayStation 4]. Digital game directed by Antoniades, T. and published by Ninja Theory.

Nintendo EAD (1985). Super Mario Bros. [Famicom]. Digital game directed by Miyamoto, S. and developed by Nintendo EAD.

Nintendo EAD (1986). The Legend of Zelda [Famicom]. Digital game directed by Miyamoto, S. and Tezuka, T., and developed by Nintendo EAD.

Nintendo EAD (1987). The Legend of Zelda [NES]. Digital game directed by Miyamoto, S. and Tezuka, T., and developed by Nintendo EAD.

O’Reilly, M. (2007). I Wanna be the Guy: The Movie: The Game [Windows]. Digital game developed by O'Reilly, M.

Oshiba, H. (2016). Trap Adventure 2 [iOS]. Digital game developed by Oshiba, H.

The Fullbright Company (2013). Gone Home [Windows]. Digital game directed by Gaynor, S. and developed by The Fullbright Company.

Ubisoft Montreal (2014). Assassin's Creed Unity [PlayStation 4]. Digital game directed by Amancio, A. and Albinet, M., and published by Ubisoft.

Budd, M. (2003). The Acquaintance Principle. British Journal of Aesthetics, 43(4), 386-392. https://doi.org/10.1093/bjaesthetics/43.4.386 


\section{References}

Bogost, I. (2011). How to do things with videogames. Minneapolis, MI: University of Minnesota Press.

Bogost, I. (2016). Play anything: The pleasure of limits, the uses of boredom, and the secret of games. New York, NY: Basic Books.

Bonello Rutter Giappone, K. (2017). “Laughing otherwise: comic-critical approaches in alternative comedy”. Journal for Cultural Research, 21 (4), 394-413.

Currie, G. (1990). The Nature of Fiction. Cambridge, MA: Cambridge University Press.

Crilly, N., Good, D., Matravers, D., \& Clarkson, P. J. (2008). "Design as Communication: Exploring the Validity and Utility of Relating Intention to Interpretation”. Design Studies 29.5, 425-457.

Flanagan, M. (2009). Critical play: Radical game design. Cambridge, MA: The MIT Press.

Ford, D. (2018). “Speedrunning: Transgressive Play in Digital Space”. Proceedings of the 2018 DiGRA International Conference, July 25-28, Turin, Italy.

Gualeni, S. (2016). “Self-reflexive Videogames: Observations and Corollaries on Virtual Worlds as Philosophical Artifacts”. G|A|M|E - The Italian Journal of Game Studies, 5 (1).

Gualeni, S. (2019). "On the de-familiarizing and re-ontologizing effects of glitches and glitchalikes”. Proceedings of the 2019 DiGRA international conference, Kyoto (Japan), August 6-10, 2019.

Gualeni, S.; Fassone, R.; Linderoth, J. (2019). “How to Reference a Digital Game”. Proceedings of the 2019 DiGRA international Conference, Kyoto (Japan), August 6-10, 2019.

Kafai, Y. B., Fields, D. A., \& Giang, M. T. (2009). “Transgressive Gender Play: Profiles and Portraits of Girl Players in a Tween Virtual World”. Proceedings of the 2009 DiGRA International Conference, September 1-4, 2009, London, UK.

Kazmierczak, E. T. (2003). "Design as Meaning Making: From Making Things to the Design of Thinking”. Design Issues, 19 (2), 45-59.

Keighley, G. (2012) [2001]. “The Final Hours of Metal Gear Solid 2: Sons of Liberty”. Available online at: https://www.gamespot.com/articles/the-final-hours-of-metal-gear-solid-2-sons-ofliberty/1100-6376810, retrieved on March the $6^{\text {th }}, 2021$.

Jenks, C. (2003). Transgression. London, UK: Routledge.

Jørgensen, K. \& Karlsen, F. (eds.) (2019). Transgression in Games and Play. Cambridge, MA: The MIT Press.

Linderoth, J. (2012). "Why gamers don’t learn more: An ecological approach to games as learning environments”. Journal of Gaming \& Virtual Worlds, 4 (1), 45-62.

Nguyen, C. T. (2020). Games: agency as art. Oxford, UK: Oxford University Press.

Paterson, E., Simpson-Williams, T., \& Cordner, W. (2019). Once Upon a Pixel: Storytelling and Worldbuilding in Video Games. Boca Raton, FL: CRC Press.

Pötzsch, H. (2019). "Forms and Practices of Transgressivity in Videogames: Aesthetics, Play, and Politics”. In Transgression in Games and Play, Jørgensen, K. \& Karlsen, F. (eds.). Cambridge, MA: The MIT Press.

Purslow, M. (2017). “Hellblade’s permadeath bluff is “not as simple as people think””. Web article available online at: https://www.pcgamesn.com/hellblade-senuas-sacrifice/hellbladepermadeath-fake, retrieved on March the $6^{\text {th }}, 2021$.

Rapp, B. (2007). "Self-Reflexivity in Computer Games: Analyses of Selected Examples”. SelfReference in the Media, 253-265.

Sageng, J. R. (2015). “Agential Properties in Computer Games”. In Philosophy of Emerging Media: Understanding, Appreciation, Application, Floyd, K. and Katz, J. E. (eds.). Oxford (UK): Oxford University Press.

Schmid, W. (2009). “Implied author.” In Handbook of Narratology, Hühn, P., Pier, J., Schmid, W., Schönert, J. (eds.). Berlin (Germany): De Gruyter, 161-173.

Tanenbaum, J. (2013). “How I Learned to Stop Worrying and Love the Gamer: Reframing Subversive Play in Story-Based Games”. Proceedings of the 2013 DiGRA International Conference, August 26-29, Atlanta, Georgia, USA. 
Traverso, M. (2019). “It's ok to lie about your game”. Blogpost available at: https://big-breakfastcollective.itch.io/waldoio/devlog/94465/its-ok-to-lie-about-your-game, retrieved on March the $6^{\text {th }}, 2021$.

Van de Mosselaer, N. \& Gualeni, S. (2020). "The Implied Designer and the Experience of Gameworlds”. Proceedings of the 2020 DiGRA international Conference, Tampere (Finland), June 2-6, 2020.

Waszkiewicz, A. (2020). “'Together They Are Twofold’: Player-Avatar Relationship Beyond the Fourth Wall”. Journal of Games Criticism, 4 (1).

Wilson, D., \& Sicart, M. (2010). "Now it's personal: on abusive game design”. Proceedings of the 2010 FDG International Conference in Monterrey, California, USA.

Youngblood, J. (2017). “'I Wouldn't Even Know the Real Me Myself': Queering Failure in Metal Gear Solid 2”. In Shaw, A. \& Ruberg B. (eds.). 2017. Queer Game Studies. Minneapolis, MN: University of Minnesota Press.

Zagal, J. P., Björk, S., \& Lewis, C. (2013). "Dark patterns in the design of games”. Proceedings of the 2013 FDG International Conference, May 14-17, Chania, Crete, Greece. 